\title{
Study on Development Strategy of Tourism Industry in Jiangxi Province Based on Boston Matrix
}

\author{
LUO Renwenya ${ }^{1, \mathrm{a}}$, LIU Xia ${ }^{2, \mathrm{~b}}$, WAGN Junyong ${ }^{2}$, DING Lan ${ }^{2}$, JIN Jiaqi ${ }^{2}$ \\ ${ }^{1}$ School of Economics and Management, Jiangxi University of Traditional Chinese Medicine, Nanchang, Jiangxi, China; \\ ${ }^{2}$ Social Medicine, Associate Professor, Jiangxi University of Traditional Chinese Medicine, Nanchang, Jiangxi, China;
}

\begin{abstract}
It has become an important economic development strategy of Jiangxi Province to promote the development of regional economy through the development of tourism industry. However, due to the difficulties brought by the environment and its own limitations, local development is not coordinated and lacks targeted strategies. Based on the development data of tourism industry in Jiangxi Province from 2010 to 2014, 2014 to 2018, this paper constructs the Boston matrix of tourism market in Jiangxi Province, analyzes the competition situation, explains and analyzes the seven changes of the Boston matrix.
\end{abstract}

\section{Introduction}

With the continuous improvement of our national economic income, people's leisure time and consciousness are gradually enhanced, which promotes the development of tourism industry. Jiangxi Province is rich in tourism resources, tourism industry has become an important part of the industrial structure of Jiangxi Province, which is of great significance in the shift of regional economy from high speed growth to high speed growth. However, the development of tourism industry in Jiangxi is not coordinated, its rich tourism resources and good economic development situation are not balanced, and tourism resources have great potential to tap ${ }^{[1]}$. In order to meet the needs of the development of tourism industry, with the help of Boston matrix theory, this paper makes a quantitative comparative analysis of the tourism industry in Jiangxi Province, in order to determine the advantage market, make up the short board market, and carry on the advantage support.

Therefore, this paper takes the tourism industry of 11 cities in Jiangxi Province as the research object, uses the Boston matrix model to divide the tourism status of each city in our province, and finally formulates the tourism development strategy according to the tourism development situation and tourism potential of each city.

\section{Materials and Methods}

\subsection{Boston Matrix}

Boston Matrix (BCG) is a method to analyze and optimize the existing market business portfolio. China's Li Jingyi et al .2002) first put forward the tourism market competition model on the basis of this model and

author: LUO Renwenya 2679560557@qq.com

bCorresponding author: LIU Xia xiajun123671@163.com applied it to the of tourism market analysis ${ }^{[2]}$. According to the market share and growth rate of tourism industry, this method is divided into four quadrants: Taurus market, star market, problem market and thin dog market, and the status of tourism areas in different quadrants has the of mutual transformation ${ }^{[3]}$. This paper proposes the corresponding strategy for the enterprises. Through the analysis and comparison of different types of tourism market, enterprises can understand the present situation of tourism industry and predict future market changes, and then adopt different types of strategies to allocate enterprise resources reasonably and limited to achieve enterprise objectives.

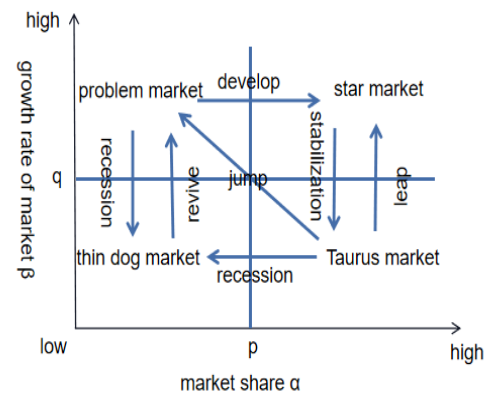

Figure 1: Boston Matrix

\subsection{Data sources and Indicator selection}

The data of this paper mainly come from Jiangxi Statistical Yearbook 2010-2018 and the Statistical Bulletin of National economy and Social Development.In this study, four indexes of inbound tourists, international tourism foreign exchange income, domestic tourists and domestic tourism income are used to reflect the market share of tourism industry in Jiangxi Province, and the average development speed of four market share indexes 
is used to reflect its market growth rate.

\subsection{Data-processing methods}

(1) Calculation method of index development speed. According to the calculation formula of the average development speed of ring comparison, the growth of tourism market in 4 indexes in various places (2010-2014/2014-2018) is calculated respectively.

$$
\overline{X_{i j}}=\sqrt[n]{x_{i j}^{t} / x_{i j}^{0}} \times 100 \%
$$

Among them, $\mathrm{Xij}$ is the average development rate of the $\mathrm{i}$ index of the $\mathrm{j}$ prefecture, The $x^{t}{ }_{i j}, x_{i j}^{0}$ is the $\mathrm{i}$ index end-stage and base period of the $\mathrm{j}$ prefecture and city respectively.

(2) Standardization of data. In order to solve the problem of inconsistency of raw data units, the linear transformation of raw data by standardization is studied before the calculation of comprehensive index.

$$
\begin{aligned}
& x_{i j}^{\prime}=\frac{x_{i j}-\min \left(x_{i}\right)}{\max \left(x_{i}\right)-\min \left(x_{i}\right)} \\
& x_{i j}^{\prime}=\frac{\max \left(x_{i}\right)-x_{i} j}{\max \left(x_{i}\right)-\min \left(x_{i}\right)} \\
& \mathrm{i}=1,2,3, \mathrm{n} ; \quad \mathrm{j}=1,2, \ldots, \mathrm{m}
\end{aligned}
$$

where the $x^{t}{ }_{i j}$ represents the raw data of the i index of the $\mathrm{j}$ prefectural city, and the $\min \left({ }^{x_{i}}\right)$ $\min \left(x_{i}\right), \max \left(x_{i}\right)$ represents the minimum and maximum value of the data of the 11th prefectural city, respectively; the $x_{i j}^{\prime}$ represents the standardized value of the $i$ index of the first prefectural city.

Calculation of the tourism market occupancy index and growth index. To comprehensively use four indicators to reflect the development of local tourism markets, the coefficient of variation method is used to calculate the index weight, and the standardized data of the four indicators are weighted and summed up. Calculate the local tourism market possession index (expressed in $\alpha$ ), tourism market growth index (expressed in $\beta$ ).

First, the calculation of index weight, using the coefficient of variation method.

$$
C V_{\mathrm{i}}=\frac{S_{i}}{\bar{X}_{i}}
$$

The $S_{i}$ is the standard deviation of a certain index value of 11 cities, and the $\bar{X}_{i}$ is the average of a certain index value of 11 cities.

$$
\begin{array}{r}
S_{\mathrm{i}}=\sqrt{\frac{\sum\left(x_{i j}-x_{i}\right)^{2}}{m-1}} \\
\bar{x}_{t}=\sum x_{y} / m
\end{array}
$$

Second, the calculation of comprehensive index. The weighted sum method is used to calculate the $\beta$. of market possession index $\alpha$, tourism market growth index.

$$
\begin{aligned}
& \alpha_{j}=\sum C V_{i} \times x_{i j}^{\prime} \\
& \beta_{\mathrm{j}}=\sum C V_{i} \times \bar{x}_{i j}^{\prime}
\end{aligned}
$$

\section{Results \& Discussion}

\subsection{Results}

\subsubsection{Analysis of Competition in Tourism Market of Jiangxi Province}

By means of formula (1),(2) and coefficient of variation, the market share and market growth rate of 11 cities in Jiangxi Province from 2010 to 2014 are calculated. The application formula (5) calculates the tourism industry growth rate to obtain the result as shown in figure 3 .

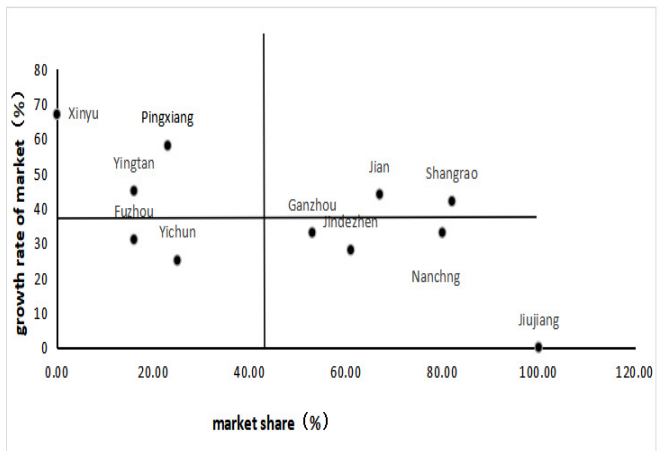

Figure 2 Competition in Tourism Market of Jiangxi Province 2010-2014

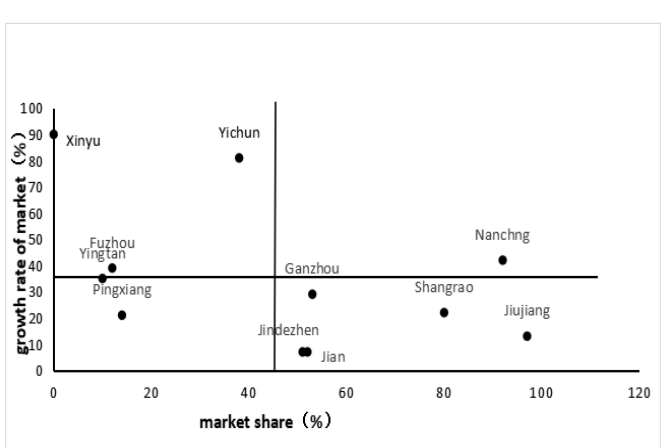

Figure 3 shows the competitive state of tourism market in Jiangxi Province from 2014 to 2018

The first stage :2010-2014 belongs to the thin dog market is Fuzhou and Yichun; belongs to the small child market is Xinyu, Yingtan and Pingxiang; belongs to the star market is Ji'an and Shangrao; belongs to the Taurus market is Ganzhou, Jingdezhen, Nanchang, and Jiujiang.

The second stage :2014-2018 belongs to the thin dog market is Yingtan and Pingxiang; belongs to the small child market is Xinyu, Yichun and Fuzhou; belongs to the star market is Nanchang; belongs to the Taurus market is Ganzhou, Ji'an, Jingdezhen, Shangrao and Jiujiang. 


\subsubsection{Changes in competition patterns in the tourism market}

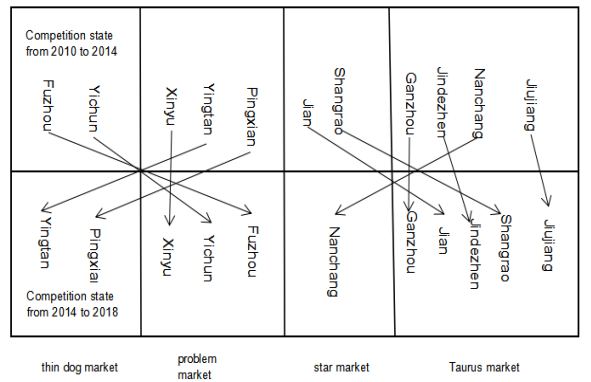

Figure 4 Changes in the Competition Pattern of Tourism Markets in Jiangxi Province

The following are the changes in the tourism market in Jiangxi Province in the past eight years:

Decline: the transformation of the small child market $\rightarrow$ the thin dog market, while Yingtan and Pingxiang, originally in the small child market, declined to the thin dog market in the second stage.

Recovery: the transformation of the thin dog market $\rightarrow$ the young child market, and Fuzhou and Yichun, originally in the thin dog market, recovered to the young child market in the second stage.

Stability: the transformation of star market $\rightarrow$ Taurus market originally developed into Taurus market in Ji'an and Shangrao in the second stage of star market.

Leap: Taurus market $\rightarrow$ the transformation of star market, originally in the Taurus market Nanchang in the second stage to the star market.

At present, there is no tourism market development, retreat, jump three kinds of changes jump.

During the past eight years, the trend of competition in Jiangxi Province's tourism industry market basically accords with the natural transfer process of figure 1, thin dog market, young child market, star market and Taurus market ${ }^{[3]}$.

\subsection{Discussion}

(1)The Taurus market is growing.

The Taurus market in 2010-2014 includes Ganzhou, Jingdezhen, Nanchang and Jiujiang. In 2014-2018, Shangrao and Ji'an were added, with a high market share of more than 45 percent, while the market growth rate was low, less than 35 percent. The growth rate of Ji'an and Jingdezhen is $7 \%$. We should develop stable strategy, stabilize market share and invest in star market. The second stage Nanchang smoothly entered the star market, indicating appropriate measures to innovate demand.

(2)Star market gap.

In 2010-2014 in the star market are Ji'an and Shangrao, market share and market growth rate are high, very potential for development. With the development of Ji'an and Shangrao ,2014-2018 has been transformed into Taurus market, which shows that it has seized the opportunity of development, expanded market share and enhanced the competitive position of tourism industry ${ }^{[4]}$. Nanchang entered the star market in the second stage.
(3)There is a general between the lean dog market and the young child market ${ }^{[5]}$.

From 2014 to 2018, Fuzhou and Yichun, which are in the thin dog market, are transformed into the young children market, with high growth rate, low share and potential for development, but there are problems in market expansion. We should actively develop such markets, while ensuring their market growth rate, expand their market share so that they can be transformed into star markets. Yingtan and Pingxiang in the young children's market are returned to the thin dog market, the market belongs to the recession period, failed to take effective measures to increase its market growth rate and market share, should develop characteristic tourism to increase core competitiveness. The two stages of Xinyu belong to the market of young children, but the market growth rate is increasing, the market share of the first stage is 67 and the second stage is 90 .

\section{Conclusion}

\subsection{Tourism market that should be vigorously developed}

According to the Boston matrix model, we should further plan the star market with leap potential. As the provincial capital of Jiangxi Province, Nanchang has maintained a high growth rate in tourism market share and growth rate, which has made great contributions to the development of tourism industry in Jiangxi Province. If the high market growth rate wants to maintain high market share, it needs that the development of the market should not rely too much on the existing advantages ${ }^{[6]}$. It should rely on good transportation location and tourism industry foundation, integrate tourism resources and innovate constantly. Therefore, we should maintain investment to make it form a scale and expand its influence.

\subsection{Maintaining the current tourism market}

For such markets, the government should maintain the existing level and ensure the share and growth rate of the tourism market. Such markets mainly include: the stable development of Taurus market from the star market and the unchanged Taurus market, such as Ji'an, Shangrao and Ganzhou, Jingdezhen, Jiujiang. The developed Taurus market-Jian and Shangrao have brought considerable financial revenue to the local area and are important pillars to support the development of regional industries. Because of its increasing market share in recent years, the government should expand the market scale of this type, so as to increase the market share of tourism and accumulate the potential of tourism market. At the same time, the government can also according to the characteristics of local tourism resources, diversified development, to maintain the market competitiveness of the market to promote the development of other local industries, this type of market government should support more. In addition, for Ganzhou, Jingdezhen and Jiujiang, where the market has not changed, high market share is the main source of government revenue, but this 
kind of market growth rate is not high, the development potential is limited, tourism industry should not only guarantee its market share, but also tap new tourism growth points and increase market competitiveness ${ }^{[7]}$.

\subsection{Analysis of the changing tourism market}

This kind of market has the characteristic of low market share and high market growth rate ${ }^{[7]}$. Therefore, because its market share is low and the economic benefit is not high, it is necessary to analyze its development mode according to its own characteristics. Such markets are mainly: from the recovery of the thin dog market to the market of young children in Fuzhou, Yichun and has been in the market of young children Xinyu. In view of the rapid growth of tourism industry in the three cities and the lack of development stamina caused by low market share, sufficient market research and industrial planning should be carried out according to the characteristics of the three cities. At the same time, the government pays more attention to tourism industry and invests effectively. Yichun can cooperate with Xinyu to build a big city to build a core city in the South Corridor, which is conducive to the rise of central Jiangxi. Fuzhou relies on the strong cultural background, closely links the Changjiu integration and Xiangpu railway economic belt, and takes Linchuan culture as the main line to develop the cultural tourism city of the hometown of talent. Three cities develop together, give play to "tourism" and other core attractions of modern industrial tourism cities.

\subsection{Tourism market to be abandoned}

During the period of 2014-2018, Yingtan and Pingxiang belong to the market of thin dog from the decline of small child market. We should analyze the causes of its decline in time, choose the development strategy according to the situation, and be ready to give up. The thin dog market belongs to the "double low" market, which can neither produce huge economic benefits nor develop potential. In view of this situation, we should find another way out and innovate. As an important transportation hub in East China, Yingtan has a small resident population and can become a leisure tourism city. Relying on Wuyi Mountain, Huangshan Mountain, Lushan Mountain, Jinggangshan, Jingdezhen, Sanqing Mountain, Qiandao Lake and other famous scenic spots to form a large tourism plate center to attract leisure tourists. Pingxiang, as a central city and an important industrial base in the marginal region of Hunan and Jiangxi, has its own tourism resources. However, because of the excessive exploitation of coal industry and the collapse of pillar industry, the strategic focus should be on the tertiary industry, increase the investment of tourism funds and the development of tourism resources, and promote the development of industry by tourism ${ }^{[8]}$.

\section{Acknowledgments:}

Project funds: 1050 Talent Project, Jiangxi University of Traditional Chinese Medicine

\section{References}

1. Jiangxi Bureau of Statistics. Jiangxi Provincial Economic and Social Development Statistics Bulletin 2020, Jiangxi Provincial Bureau of Statistics 2020.3.17

2. Li Jingyi, Sun Gennian. A Study on the Competition Model and Its Application in Tourism Market [J].] and Resource Science ,2002(06):91-96.

3. Xie Weiguang, Chen Xiong, Gu Song. An Analysis of the Entry Tourism Market in Zhejiang Province Based on Boston Matrix Model [J].]; and East China Economic Management 23(03):18-21.

4. Zhang Yufeng, Yuan Angui, he Guanghan. An Analysis of Competition in Sichuan Entry Tourism Market Based on Boston Matrix Theory Model [J]. Ecological Economy ,2008(03):95-97.

5. Peng Yan, Xie Dongming. A Quantitative Study on the Coordinated Development of Tourism Industry and Regional Economy Based on Case Study [J].] of China Ecological Economy ,2015,46(06):81-86.

6. Zhang Hengli. City [N].] of Mountains and Rivers Nanchang Daily ,2020-08-17(002).

7. Cai Jin, Tan Jian, Kang Jing. A Study on the Business Development Strategy of Public Hospital Departments Based on Boston Matrix [J].]; and Medicine and Society 32(05):47-51.

8. Zhang Hengli. City [N].] of Mountains and Rivers Nanchang Daily ,2020-08-17(002). 